This is an author produced version of a paper published in Urban Forestry \& Urban Greening. This paper has been peer-reviewed but may not include the final publisher proof-corrections or pagination.

Citation for the published paper:

Anna Maria Pálsdóttir, Ulrika K. Stigsdotter, Dennis Persson, Petra Thorpert, Patrik Grahn. (2018) The qualities of natural environments that support the rehabilitation process of individuals with stress-related mental disorder in nature-based rehabilitation. Urban Forestry \& Urban Greening.

Volume: 29, pp 312-321.

http://dx.doi.org/10.1016/j.ufug.2017.11.016.

Access to the published version may require journal subscription.

Published with permission from: Elsevier.

Standard set statement from the publisher:

(C) Elsevier, 2018 This manuscript version is made available under the CC-BY-NC-ND 4.0 license http://creativecommons.org/licenses/by-nc-nd/4.0/

Epsilon Open Archive http://epsilon.slu.se 


\title{
The qualities of natural environments that support the rehabilitation process of individuals with stress-related mental disorder in nature-based rehabilitation
}

\author{
Anna María Pálsdóttir ${ }^{1 *}$, Ulrika K. Stigsdotter ${ }^{2}$, Dennis Perqsson ${ }^{3}$, Petra Thorpert ${ }^{4}$ and Patrik \\ Grahn ${ }^{1}$ \\ ${ }^{1}$ Department of Works Science, Business Economics and Environmental Psychology, Swedish University of \\ Agricultural Sciences, Alnarp, Sweden; \\ 2 Department of Geosciences and Natural Resource Management, University of Copenhagen, Denmark and \\ ${ }^{3}$ Department of Health Sciences, Occupational Therapy and Occupational Science, Lund University, Lund, \\ Sweden, \\ ${ }^{4}$ Department of Landscape Architecture, Planning and Management, Swedish University of Agricultural \\ Sciences, Alnarp, Sweden. \\ *Corresponding author
}

Tel.: +46 40 415536; E-mail address: anna.maria.palsdottir@ slu.s

\section{Highlights}

- Social quietness is an important quality of supportive environment

- Restorative environment should offer the components: Being away, Extent, Fasciation and Compatibility.

- Perceived sensory dimensions such as Serene, Nature, Prospect, Refuge and Space seem to be of equally importance in supportive environment.

\section{Introduction}

Natural environments can have a positive impact on human health and well-being (Mitchell and Popham, 2007; Stigsdotter, et al. 2010; Hartig et al. 2014), restore cognitive functions (Ottosson and Grahn 2005; Kaplan 1995), improve self-reported health (Björk et al. 2008; Maas et al., 2009) and facilitate stress restoration (Tyrväinen et al. 2014; Ulrich et al., 1991; Van den Berg et al., 2010). Certain characteristics and qualities in natural environments are more beneficial than others as resources for enhancing mental restoration (Grahn et al. 2010; Kaplan 2001), with restoration being defined as "the process of renewing, recovering or re-establishing physical, psychological and social resources or capabilities diminished in ongoing efforts to meet adaptive demands" (Hartig, 2004, p. 273). Attention Restoration Theory (ART) attempts to explain how depleted directed attention can be re-energized through restorative experience of effortless soft fascination in nature (Kaplan 1995, 2001), and how nature, particularly, provides high potential for directed attention restoration (Hartig et al. 2003; Ottosson, 2007). ART presents four hypothesized properties that are likely to contribute to a supportive environment: being away (mentally and physically, moving to a totally different place), extent (the site should be large enough to give space to the experience of scope and connectedness), fascination (place that endows with fascination and stimuli to capture and hold one's' attention - soft 
fascination) and compatibility (support the needs and inclination of the users) (Kaplan, 2001; Kaplan et al., 1989). Kaplan (1992) argues that all these qualities are required in a good supportive environment. To begin with, one needs to seek out an environment that means a total break - a "being away" - from the everyday environment with its demands you need restoration (OR to be restored)from. However, for this quality to work properly, it needs in addition to have the quality "extent". These two qualities are however not sufficient to provide restoration from directed attention fatigue. The area must also provide opportunities for soft fascination. Finally, to provide a supportive environment for the visitor, it needs to be compatible (Kaplan, 1992). This last, vital and much needed quality what is it about? How could a supportive, compatible environment be defined?

Studies have identified eight main qualities, so-called perceived sensory dimensions (PSD) that visitors in urban green spaces prefer and which are also important for stress reduction (Grahn, 1991; Grahn et al. 2005; Grahn and Stigsdotter, 2010). These eight properties are: Serene (peaceful, silent, safe and secure); Nature (fascination with wild nature); Rich in species (variety of species of flora and fauna); Space (like entering another world, a coherent one); Prospect (open space with vistas); Refuge (a sanctuary, a secluded place); Social (a social arena); and Culture (signs of human labour and human values throughout history). In the context of naturebased rehabilitation (NBR), three 'PSDs' have been identified as components of a supportive environment: refuge, prospect and serene (Pálsdóttir et al., 2011), all regarded as properties of person-environment interaction and not merely of the physical environment (Grahn \& Stigsdotter, 2010; Grahn, et al., 2010; Kaplan, 2001).

In 2002, a two-hectare specially designed rehabilitation garden was established at the campus of the Swedish University of Agricultural Sciences in Alnarp, Sweden, set up as a living laboratory for studying the effects of nature-based rehabilitation for individuals with stressrelated disorders and if a natural environment can support the rehabilitation process (Grahn et al., 2010; Grahn et al., 2017; Stigsdotter and Grahn, 2003). The garden design was based on different theories on nature's positive effects on health and meaningful occupations. The garden is divided into different garden 'rooms', each with special properties of supportive environment for supporting the participants' rehabilitation process, as well as rooms facilitating meaningful horticulture and garden activities (Stigsdotter \& Grahn, 2003 The role of natural environments at Alnarp rehabilitation Garden has been described and discussed in relation to participants own experience of the recovery process during 12 weeks rehabilitation. The natural environment was described as important support where the participants could seek refuge and comfort during the ongoing rehabilitation process. The natural environment became the arena for salutogenic processes, self-regulation and mental recovery (Pálsdóttir et al. 2014). Yet, little is known about the physical qualities per se in the natural environments that can support the rehabilitation processes guided by a 
professional rehabilitation team (Tenngart Ivarsson, 2011). Therefore, there is a great need to identify and describe specific qualities of natural environments that may support health processes or outcomes (Bratman et al., 2015; Korpela and Staats, 2014; Poulsen et al. 2015).

The aim of this study was to identify specific locations (compatible supportive environments) and their qualities which clients undergoing nature-based rehabilitation experience as supportive for their rehabilitation process.

\section{Methods}

This study was designed as longitudinal single-case study (Robson 2011; Yin, 2009) using a narrative research approach based on interviews and location mapping (Kvale, 1996). As weather differs between years, and the fact that a garden is not a static phenomenon, the data were collected over a period of five years: in 2007 and again during the years 2009 to 2012. The rehabilitation program did not change during these years, and aside from the fact that some plants became larger, the garden did not change.

\section{The programme}

The NBR programme at the Alnarp Rehabilitation Garden was designed as group therapy, supported by a transdisciplinary team, integrating four major therapy forms: occupational therapy, physiotherapy in the form Rosen therapy, psychotherapy and horticultural therapy (Pálsdóttir et al., 2014; Lavesson, 2013). Each year was divided into four 12-week rehabilitation periods: I) winter to spring; II) spring to summer; III) summer to fall; and IV) fall to winter. The weekly programme was managed by an occupational therapist assisted by a horticulturist. All therapeutic activities were performed outside, except when the weather was unfavourable; in the latter cases these took place in the main building or in one of the glasshouses (Pálsdóttir et al. 2014).

\section{Study context}

The garden contains places for work as well as rest and contemplation, and can be divided into two major areas: the Nature Area (informal and non-cultivated, indicated in green on Figure 1) and the Cultivation and Gardening Area (formal and cultivated, indicated in blue on Figure 1). The garden contains evergreen and deciduous trees and shrubs, as well as a variety of spring/fall bulbs, perennials and annuals. The size, form, colours and texture of plants differ in order to stimulate and awaken the different senses, with an emphasis on seasonal variation (Pálsdóttir, 2014). The garden is fenced off, with a substantial gateway as its main entrance, and the area is closed to visitors during the time participants are hosted in the garden. (Stigsdotter and Grahn, 2002, 2003 and Tenngart Ivarsson, 2011).

\section{Participants}

The participants were all being treated for stress-related mental illnesses. The inclusion criterion for participating in the programme was one of the following International Classification of Disease (ICD-10) codes as the primary diagnosis: psychiatric diagnosis of adjustment disorder 
and reaction to severe stress (ICD-F43 including 43.8a exhaustion disorder) or depression (ICD-F32.0, F32.1). The exclusion criterion was known drug or alcohol abuse. Prior to admission to the programme, a medical examination was performed to ensure that the inclusion criterion was fulfilled. All participants were Swedish residents. In terms of their level of education and professional status, the client group included various occupations such as academics as well as practical occupations (Währborg et al 2014).

\section{Data collection}

This longitudinal single-case study (Yin, 2009) concerned the garden area and the NBR intervention as one phenomenon. A narrative interview approach was chosen (Robson, 2011) in order to capture complex phenomena of the supportive locations (Robson, 2011). Altogether, 59 former clients participated in a one hour semi-structured interview (50 women and 9 men). All participants signed written consent before entering the study and were informed that they could withdraw from the study at any point without explanation (World Medical Association Declaration of Helsinki, 2013). The first author conducted all the interviews, within a month after the clients had ended their rehabilitation, which were recorded and transcribed verbatim.

A map of the garden area was used to encourage expression of the storyline and ensure accuracy about the locations being discussed. After the interview, some participants wanted to show their locations of support in situ. All places identified as supportive were photographed for later illustration.

All interviews were conducted in a secluded and private setting at the Rehabilitation Garden with no outsiders present, and where all the participants felt that their confidentiality was protected. The participants' behaviours and other contextual aspects of the interview were observed and documented in the field notes. All interviews were recorded and transcribed as soon as possible after they had been completed. In the transcribed text, field notes were added to include fresh impressions, body language, nuances and atmosphere that otherwise could have been lost (Hayes, 2000). Both the patterns and themes that appeared immediately during the interview itself, and tones in the voice that could be heard when listening through the recorded interview, were included in the analyses (Kvale, 1996; Hayes, 2000). The interviews were semistructured, which meant that a short interview manual was constructed, including some keyquestions related to the aim of the study. With backing from the manual, the interviews could focus on issues of more interpretative and descriptive nature (Hayes, 2000), with follow-up questions such as "What do you think it depends on?", "Can you explain what you mean?" and "Give some examples from this garden". Taken together, this can give the interviewees the opportunity to respond freely and in their own words.

\section{Data analysis}


In the first part of the analysis (step 1), the first author read each transcript several times to understand the text as a single whole phenomenon. Then, in step 2, all significant events related to the experience of supportive environment in the garden were distinguished and collected into a separate document.

In step 3, key experiences, written on the map, were compared to the distinguished events (from step 2) to ensure that no aspects had been left out. Based on these steps, the narratives were transferred into a matrix and broken up according to location, emotion being processed, social context (alone or together with others), occupations performed (e.g. sitting, looking at plants, walking) and description of important components and features the participants mentioned as supportive in that particular location (step 4). This was done to get an overview of the contents and functions of each location identified as a supportive environment for the rehabilitation process.

The analysis was compiled into a narrative description (story outcome) of the specific locations identified as supportive during the rehabilitation process. The material was treated as one general story, i.e., the phenomenon of supportive environment in the context of NBR at the Alnarp Rehabilitation Garden. The qualities of the supportive locations were identified, interpreted and described as physical features as well as the restorative components and PSDs.

Throughout the analysis process, emerging narratives were critically discussed with the last author who also read some of the interviews to establish his own perception of the content.

\section{Ethical considerations}

The regional ethical committee in Lund, Sweden was asked for ethical approval but the study was not considered relevant for evaluation. However, they recommended written consent before participants voluntarily entered the study.

\section{Results}

Altogether, 17 specific locations were identified as supportive environments in the garden (see Figure 1 and 2). Although many participants pointed out one specific location they felt had been supportive in their rehabilitation process, they highlighted that the garden at-large was supportive because different locations supported different needs during different phases of the 12 weeks of NBR. Some chose the entire garden as a supportive environment as they did not want to single out one particular location.

\section{Supportive locations at the Alnarp Rehabilitation Garden}

Results regarding supportive environments are presented in the order of the two main garden areas, i.e. Cultivation and Gardening Area (formal garden and cultivated area, indicated in blue on Figure 1) and the Nature Area (the informal garden and the non-cultivated area marked in green on Figure 1).

Cultivation and Gardening Area (the formal garden and cultivated area - in blue on Figure 2) 
The main gate - entrance to the garden

Participants repeatedly expressed that the main entrance to the rehabilitation garden (location 1 , Figure 2), marked the distinction between the outer world of everyday life and struggle and the inner world, the world of sanctuary and safe refuge. Once they were through the gateway and had closed it behind them, the participants experienced a strong feeling of being in another world, a world of acceptance and permissiveness. Being in a safe place, they could simply be in the state they were actually in, not having to keep up appearances like they had to in everyday life outside the garden. Many expressed that the absence of others was important: "Because there's a certain something, I can miss it sometimes sort of, anyway - this thing that when you went in through the door, the gate to Alnarp, then it's just us there. There wasn't anybody else."

\section{The Welcome Garden}

Two locations within the welcome garden were identified as supportive: the garden swing corner and the woodland corner (locations $2 \mathrm{a}$ and $2 \mathrm{~b}$ on Figure 2).

The garden swing corner. The participants described the feeling of being half hidden from the surrounding when sitting in the garden swing with a roof above, hedges on the side and behind them, and a large herbaceous bed in front of them. The two paths leading to the garden swing, situated in the corner, gave them the possibility to 'escape' if someone approached. The two paths were covered with soft bark chip; participants expressed that this gave a feeling of walking on a soft wool (do you really mean wool?) path and that, when entering it, one slowed one's pace. The plant bed is large enough to create a comfortable distance between a participant and those walking by on the passing path, and allows an avoidance of eye contact if it is not wanted. The sound of someone walking on the gravel on the surrounding pathways told when someone was coming close or was just in the distance. All these features were expressed as very important qualities of a secure and safe place. "That you can hear somebody else coming too, since there are those gravel paths in the middle. I guess that's also the main reason I haven't picked the back, because there aren't any gravel paths there. So, you don't know what's going on, I mean if I were sitting there and somebody came around the corner... I'd have thought that was a bit bothersome."

The colour scheme was described as well-balanced, consisting of soft colours in the flowerbeds, and the soft structure of the plants, as soothing and unpretentious. Here, there were no odd or bright colours (they were mostly in a blue-white scale) or hard shapes signalling demands and wearing out tired minds. "Then it's more special when it's in a place; I'd surely have thought it was too chaotic. Because when I'd actually come here it was like...that was when I was so tired and just wanted to...you didn't want to have any impressions." 
This place was used for contemplation, enjoying the sun, or just relaxing and restoring a tired body and mind. Also, when one felt sad, it was comforting to slowly swing in the garden swing and just look at the lush planting in front of the swing, or at the sky. The participants wanted to sit by themselves and not be disturbed by others.

The woodland corner (location 2b, Figure 2). Many talked about liking to hide in the corner where they could sit un-noticed by passers-by on the other side of the pond. The two walking paths gave clients the possibility to escape in case of intruders. Opposite the corner, right in front of the pond, is a wooden bench situated immediately next to the walking path passing through the area. The participants called this side 'the sunny side' and the corner 'the shady side'. Many participants said that the possibility to be able to choose a side, i.e. 'sunny' or 'shady', in one and the same location was an attractive attribute of a place. Participants mostly sought this place to be alone, and did not want to share it with others when enjoying this calm place. When they felt they had mental energy to meet others they "dared" to sit on the bench. "I want to have the place to myself to have the experience of calm. Here I stop, stand and just take in the plants, the place and the calm - I inhale everything there. How long I stayed there depended on the weather; if it was warm I liked to sit for a very long time - preferably a long time, because it felt like I was at a petrol station; yeah, you just fill up and fill up and fill up."

Participants expressed that watching the water surface, plants, small fish and insects 'minding their own business' was a soothing experience. The large stone by the pond invited one to stay, and several participants climbed up on it and sat there like "Buddha under the lotus leaf", as one participant put it. There, one could just sit, inhale the calm atmosphere and reach a meditative state. Some closed their eyes, listened to the wind or the birds while smelling the air full of "nature". This location, like the garden swing corner, was seen as a place for contemplation, calming down and restoring a tired and fragile mind. The participants mostly used this location alone, for intimate and personal interaction with nature elements for their introvert occupations.

The glass houses. Many of the participants felt cold easily, and in the colder months of the year a place was needed with a comfortable temperature where they could sit at ease and/or work at a leisurely pace. Both Grow-Point and winter garden were heated during colder periods. These places were specifically important during the colder months, as they allowed participants to enjoy fresh air and daylight in a comfortable temperature. Participants defined a comfortable temperature as not being cold and as being able to relax, as one could not relax if one was cold “Not being cold, that's important. If I'm cold, no way, I can't relax..." They repeatedly mentioned the nice feeling of being outside but at the same time inside, sheltered from the weather. The greenhouses were generally perceived as bright, open spaces without walls, where one could observe the outdoor surroundings if desired. Also, here one could work with the plants 
or just sit down and relax: "I liked the propagation but I didn't really do much of it, more often I just breathed in the environment. That gave me the feeling of calm."

Participants found the interiors of Grow-Point cosy and as containing pleasant plants, pleasant fragrance, a balanced colour scheme, generally soft, balanced sensory stimuli for tired minds, and a comfortable temperature (though sometimes too hot at the height of summer). They felt that this location was very much alive, but at the same time perceived it as peaceful, enhancing the feeling of calmness. They reported both using this location on their own for reflection and even sharing it with the group when working with the plants. "Because the environment itself is...provides a calm. But you can use that calmness to both do things and not do things. Ehm ...And just to maybe get a bit more in contact with your feelings and also be able to feel a bit more what... what should I do and what should I not do. That calm gives the possibility to think and consider things."

The cultivation beds in front of the large greenhouse

Participants described the area as a sheltered and secluded location. The old and worn-out wooden beds were perceived as charming, and the participants felt at ease here. This area was described as a quiet place, good for reflection and clearing one's mind - especially when not shared with others. "Well, these old beds for example, I sat there and thought a lot, sneaked out and cried, huh... and a bit of reflection over memories. Think a bit about what you think is bad, or think to yourself that you're so stupid; I mean this self-perception is so hard. Ehm ... and you really don't want to share that with everybody but rather just yourself.

The participants either sat in front of the greenhouse looking over the beds, or walked between the beds. Some just looked at the plants, others photographed or painted them, and some picked flowers. Which plants were on display depended on the season; e.g. in spring there were colourful spring bulbs in flower, and in late summer-early fall colourful dahlias grew in the beds. The participants mentioned that the colourful schema aroused joy in them and that it was a playful experience, but that they could only manage to be among the strong colours towards the end of their rehabilitation period, as their tired minds had difficulty handling the strong stimuli. If this colour scheme had been all over the garden, this would have been perceived as overstimulating and too demanding. "I don't know, but it's a bit exciting to think; because it was at the end of the Alnarp course that I was in the dahlias. Not at the beginning, and I don't know if it might have something to do with that because I got stronger and had the energy to take in more impressions and such". The raised cultivation beds in front of Grow-Point

Many participants mentioned that they perceived the strict form of the boxes and the distinct square structure as demanding, but that a positive thing was that the plants were positioned close to one's face. This enabled them to take notice of the plants more easily than, e.g., in the traditional vegetable garden where the plants were at their feet. “...But here it's sort of a bit 
higher so it's more inviting, actually, to go there and smell so that...I don't know, I think it's much, much, much more inviting. " Participants often talked about "spontaneous harvesting": picking herbs, vegetables and other edible plants when stopping by the raised boxes. They tasted and smelled the plants' leaves, tasting baby leaves of salad or small carrots and radishes. This was described as creative and fun, and as being "lured" into something good. As fall in Scania is quite mild, the woody herbs (e.g., sage, thyme and rosemary) stayed out in the boxes long into the fall, so participants could enjoy being outside and still touch, taste or smell them. Many participants said that if they were too sad or needed to be alone with their feelings they would not enter the area, because this place was a 'social location' - meaning one could expect to meet others here. Most often this place was shared with others, but on occasions one could also be alone here.

\section{The north terrace}

Participants mentioned needing space around them but still needing a safe place to be in. When standing on the terrace one had a view of the wide-open space toward the vegetable garden, the meadow and the sky. They saw this area as a good place to be out of sight when one needed to be alone to process all the impressions. It was experienced as safe, as one had a secure back (the main building) and a prospect over the surroundings. Participants either walked around the terrace, or stood or sat by themselves close to the northwest corner of the house, looking over the surroundings. Here, they wanted to be alone with their thoughts and feelings and hide from others. "I need space around me. Something that's in my body since I got sick - I have a kind of wall in front of me that I have not been able to go either over or around. I have a bit of a "claustrophobic" feeling. On the big terrace behind the house, there I could have the space I needed and could also see the views. I liked to stand there and did so often, just stood and looked out at the surroundings."

The large pond

Participants described this location as a calm and tranquil place, mostly embedded in vegetation and offering good possibilities to sit down to watch the surroundings undisturbed. They could move the chairs around as they pleased, or sit on the large stones without being noticed. From here they followed others moving in the garden, or just enjoyed the close-up environment. The sound of the running water, modestly dripping down the small stream, was perceived as calming and as helping to clear their mind. "I listened to the babbling water and looked out over the space when I needed to be by myselffor a while. I needed to go away for a while and be by myself a little while and digest all the impressions - there were new impressions all the time." Participants expressed a fascination for the fishes in the pond and the small lizards running around. The water's surface was an endless source of new surface reflections; from the very blue sky reflected in the water to the frosty iced surface. This was perceived as a pleasant and calming 
experience. Some participants referred to this place as their place of energy and fascination, and others spoke of a longing to dip their feet into the water and feel its freshness. The participants mostly used this place on their own when processing thoughts or just to calm down.

Nature Area (the informal garden and non-cultivated area- in green Figure 1)

The wildlife garden room - the forest garden

Many participants described how the natural appearance appealed to them, and how this was perceived as a calming and safe environment. It was described as a secluded place, embedded in lush vegetation, where one could be alone. Some participants mentioned how easy it was to hide and find a nice, sheltered place where one could "see others but not be seen". Others mentioned the restfulness of the overgrown and wild-like nature, or "wildish" as one expressed it. Many talked about how easy they could find inner peace and rest their tired mind. They said the wild attribute was undemanding and restful. "Ehm I think we humans like to put things in an order, but I think maybe it's not as restful, I don't think so - it's more a struggle in some way to be...that you...I'll say it like this: I think this is more restful, being a bit more wild and overgrown...I mean it's not...it's not wild...but 'wildish'.",

Participants told how they could move around without being heard or seen, and hide from the rest of the world. Some walked slowly or strolled around, while others just sat somewhere and enjoyed the surroundings. Some mentioned regaining the feeling of natural origin and a strong belonging to some greater whole. They also shared how they closely interacted with nature and dared to expose their deepest feelings and thoughts without hesitation. The close encounters with nature gave peace of mind. Some sat on the ground, in chairs or on wood stumps, while others preferred to lie on the ground to get even closer to the earth. "Eh...I mean partly being close to the earth on the ground that makes me calm; not always having furniture in between. Being completely on the ground, it feels like some sort of pulse from the earth, in a good way. So it happened that I 'grounded' myself. I needed to be grounded."

Some talked about the smell of grass, the taste of berries, or sounds of the wind and bird twitter and songs. In the winter they saw tracks from animals (birds and hares) in the snow. They told how they felt that nature was strongly presented in the forest garden and that here in the wild one could think without effort and find one's way back to peace and quiet. Again, participants expressed the urgent need to be alone with nature.

The outer land - the meadow, the orchards and experiment fields.

Participants clearly expressed their need of space when handling their strong emotions; the space inside a house was not large enough for all these feelings. Some had a strong need to be alone, and did not want to be seen or noticed when processing their feelings. They needed to get away and not have to relate to others around them: “...I guess it's because in some way it's about getting as far away as possible and not needing to relate to anybody else, but just being alone." Others 
expressed an urgent need for a walk, alone, after an organized treatment in the 'NBR' programme, to release their emotions. "Yeah, then I needed to move around and be left alone, and be outside and cry a lot of times. And be left alone with that and not have to be scrutinized."

Some explained how they walked hastily through the high grass in the meadow, the orchards or the experimental fields where the ground was uneven. Others mentioned struggling through thorny bushes or seeking refuge in primitive, rough places. Many participants expressed the need of privacy when processing negative feelings and emotions such as rage, anger, desperation or frustration, especially when the need to scream and/or cry out loud emerged.

The outer land - the meadow, the orchards and experiment fields - was mostly used for private moments when the participants needed to handle strong and difficult emotions.

\section{Discussion}

The purpose of this study was to investigate Alnarp Rehabilitation Garden as a supportive environment, in particular to identify specific supportive locations and their properties. The results show that Alnarp Rehabilitation Garden satisfies important demands of a restorative environment according to Kaplan (1992). When the participants entered through the gate to the garden, they experienced the liberating feeling of "being away" - the first and most needed demand (Kaplan, 1992). The gateway marked the boundary between the world of safe sanctuary and the outer world of everyday life. This landmark was of utmost importance to being away from everyday life in a safe environment (Kaplan et al. 1998; Tenngart Ivarsson and Hägerhäll, 2008; Palsdottir et al 2014). The garden, with its size, its coherence and content also meets the requirements of "extent" and "fascination". In addition, it meets the requirements of being compatible, generally speaking, for the participants needs in different situations during the rehabilitation process.

When participants are asked to point out a particularly supportive environment, many of them declare that the whole garden is supportive, because different locations supported different needs during different phases of the 12 weeks of NBR. In addition, the garden needs to have a design and content that enable flexible use. Here, participants should feel that they can be undisturbed, not having to worry about that others than fellow patients and staff will surprise them when they show themselves in a more naked state of fatigue and of being unhappy, even upset with grief and despair (Palsdottir, 2014; Palsdottir et al 2014).

\section{Perceived sensory dimensions}

Alnarp Rehabilitation Garden contains supportive qualities, as could be defined by PSDs, which makes it compatible. A number of studies regarding which of the PSDs is the most important for a stressed person have been implemented. Some large epidemiological studies indicate that PSD Serene is the most important (e.g. van den Bosch et al 2015), but these epidemiological studies are only comprising five PSDs; not Refuge, Social and Prospect. 
Several other studies also point out that Serene is important (e.g. Grahn \& van den Bosch 2014; Stoltz et al 2016; Stigsdotter et al 2017a; Stigsdotter et al 2017b) but emphasize to a greater extent other qualities. The majority of them demonstrate that the most important quality is Refuge, where Grahn \& Stigsdotter (2010) argue that Nature is the second most important PSD while Species Richness is the third most important. Tenngart Ivarsson (2011) suggests that Nature is the second most important PSD followed by Serene. Other studies (Palsdottir 2014; Pálsdóttir et al., 2010) maintain that Prospect is the second most important PSD followed by Serene.

\section{Refuge as a supportive property}

The results of this study support that the PSD Refuge is the most important, and also provide more guidelines as to what it is about. The Garden Swing Corner and The Woodland Corner are clear examples of places where the PSD Refuge is strongly expressed. Here, the participants feel safe, surrounded and embedded by greenery. They have an overview of the surroundings, either by being able to see if someone is coming or hear it, and there are good escape routes if someone gets too close. Participants' own expression of the need to "see but not be seen" (or, as we can interpret from the findings, to be able to hear when someone approaches - to have an auditory control over the environment - see Cerwén et al., 2016) resembles Appleton's (1975) reflection of prospect-refuge, whereby environmental preferences are explained as an evolutionary desire for survival. Hence, the PSD Refuge has a clear aspect of prospect, which gives the opportunity for visual (and/or audial) control over the surrounding environment, and at the same time being in a safe shelter, a place to hide according to Appleton (1975). These are the features the participants described as important for their introvert expression, wanting to be alone - i.e. in sheltered and safe supportive locations with a clear view of the surroundings in order to handle their various emotions. Also, Korpela et al. (2001) defined such places as favourite places, where one could escape from social pressure for emotional and self-regulation.

In both the Garden Swing Corner and The Woodland Corner another important aspect was prominent - PSD Serene. It was expressed in several ways; such as a dimmed colour scale with nothing sticking out, a sound environment where you could hear the birds and the wind rustling in the trees (Cerwén et al. 2016) and be able to feel the heat from the sun. In the beginning of the rehabilitation period the participants are in need of a soft colour scheme and later in the process, as their mental and physical power increases, they can handle stronger colours e.g., red or bright yellow and orange, but locations with those opportunities could only be in certain limited amount and in a certain place where one could visit at one's own need and desire. PSD Serene could here, and in e.g. the glasshouses often be experienced by means of moderate sensory stimulation: not too cold or hot, not too many colours or sounds. You could 
just rest and become calm, by e.g. slowly swinging in the Garden Swing Corner or sitting like Buddha in the Woodland Corner. At both these places PSD Species Richness is also an evident feature in the form of herbs, flowers and birds, and in the pond at Woodland Corner, with fishes and insects "minding their own business". This could be interpreted as PSD Refuge with an aspect of prospect, and Serene followed by Species Richness are prominent qualities in these locations. Stigsdotter et al. (2017) found similar places to be optimal restorative environments. At North Terrace, Refuge is also an evident PSD: being able to look out over the wide-open spaces, where nobody discovers you and at the same time you can feel that you are not trapped, there is plenty of space around you.

In the Forest Garden, the PSD Refuge is similarly strongly pronounced. Here, the participants explain that the advantage of the place includes the opportunities to move around in the area, at the same time that they can see the surroundings without being seen or heard. In addition, one can experience a strong sense of the PSD Wild Nature. The participants state that they want to experience a wild or at least "wildish" nature: a nature the participants want to be alone with. Some participants have even laid themselves down on the ground to experience this stronger. Another advantage of the Forest Garden the visitors emphasized, was that they could experience PSD Serene in the form of being able to listen to the wind and the birds, smell the grass, taste berries and discover signs of animals both in summer and in winter. Hence, PSD Species Richness is also a noticeable quality.

Other supportive places, such as "the cultivation beds in front of the large greenhouse," "the large pond" and "the outer land- the meadow, the orchards and experimental fields" have PSD Refuge as an important feature, even if it is not so prominent. In these places, participants preferably want to be by themselves.

We can interpret the result as the PSD Refuge needs a clear facet of prospect to be restorative, and in addition there is a strong need for escape routes. There seems to be a delicate balance between prospect and refuge for the visitor to feel safe and comfortable. Gatersleben and Andrews (2013) found that walking through natural environments with a too high degree of refuge was perceived as less restorative than natural environments with a high degree of prospect. This due to a lack of feeling comfortable and safe in the environment. However, PSD Prospect, which is about open spaces and vistas, should at least in the context of Rehabilitation Gardens have its name changed to PSD Open Spaces and Vistas, for not being confused with the content of PSD Refuge.

\section{Other PSDs as supportive properties}

At some supportive locations, PSD Refuge seems not have the same decisive consequence. These places are important later in the participants' rehabilitation process. Common to some of them is that the PSD Serene and the PSD Species Richness are salient. 
The participants claim that they choose to stay at "The cultivation beds in front of the large greenhouse," and "The large pond" because they are tranquil places. At "The large pond" the participants got the Serene atmosphere by listening to the sounds of running water, and watching the clear and calm water, which shimmered in different colours depending on the weather and season. In the winter, the light reflected in the ice. Both places are Rich in Species; "The cultivation beds in front of the large greenhouse" having lots of flowers and herbs; "The large pond" having fishes and other species attached to the water. In addition, "The raised cultivation beds in front of Grow-Point" was a place some participants chose to visit from time to time owing to its Species Richness - in spite of its quite demanding distinct square structure. They went there for "spontaneous harvesting", tasting baby leaves of salad or small carrots and radishes, which were cultivated in raised beds close to the visitors' faces.

Many participants also needed to visit "The outer land - the meadow, the orchards and experiment fields" because they felt an urgent need for PSD Space; to get away and not have to relate to others. They needed to be alone with their upset feelings.

Participants did not stress PSD Culture, PSD Social or PSD Prospect (or perhaps this quality should be renamed to PSD Open Spaces and Vista) as qualities that supported them in their rehabilitation. All these qualities either exposes the participants of the eyes of others, or let the participants themselves be confronted by human activities and values. This can be valuable at the very end of the rehabilitation, but certainly not at the beginning when the situation is completely reversed. In the beginning, the participants cannot cope with people's activities because they do not possess the energy to handle visible evidence of people's activities. Findings highlight the participants' need to be alone with nature, undisturbed by the presence of others, when handling their emotions in the supportive locations in the rehabilitation garden. This is hereby referred to as Social quietness (Pálsdóttir, 2014, Cerwén et al., 2016). Korpela and Staats (2014) also discuss the concept of solitary restoration in nature and the effects on the restorative experience if shared with others, offering evidence that the company may enhance the experience of restoration, but also point out the potential risk of degraded restorative effects if one's attention is drawn away from the environment. The current study's results demonstrate participants' urgent need of solitary engagement with nature when processing their emotions and experiencing mental restoration. Due to their illness, the participants suffered (amongst other symptoms) from cognitive and social impairments (Jonsdottir et al., 2013), and many mentioned having difficulties relating to other people, caused by their mental exhaustion. For stressed individuals, a low presence of the social dimension is associated with more restorative effects in an urban green environment (Grahn and Stigsdotter, 2010; Ottosson and Grahn, 2008). Social withdrawal (Korpela, 2002), combined with the choice of a supportive location with the quality of social quietness seems to allow participants to fully engage with nature and enjoy its 
benefits, given the fact that the feeling of being safe and secure is already in place (Staats and Hartig, 2004; Palsdottir et al 2014). Therefore, in the context of NBR, the absence of demands for social feedback (Korpela and Straats, 2014) appears to be an equally important quality of supportive locations as their actual physical features (Scopelliti et al., 2004).

\section{Conclusion}

In summary, the study shows that Alnarp Rehabilitation Garden is a restorative environment, consistent with the findings of Kaplan (1992). Participants already on arrival get a feeling of 'Being Away' when they enter through the gate. The garden has a clear coherent identity, where participants have opportunities to take excursions to the meadows and orchards in the area without feeling concern that they leave the area; i.e. the Rehabilitation Garden has 'Extent'. The PSD Space represents a spacious and free room, a restful feeling of entering a coherent world (Grahn and Stigsdotter, 2010). We interpret 'Extent' as the whole Rehabilitation Garden is characterized by PSD Space, and that this PSD is particularly salient in a couple of important supportive locations - "Forest Garden" and "The Outer Country". Some physical features of these supportive locations related to PSD Space: secluded and sheltered semi-open spaces, offering varied ground cover; free growing vegetation including both shrubs and trees with blurred borders of hedges; edible plants; rich flora and fauna; no odd or strong colours in the vegetation, some sitting facilities; and no formal paths. In these locations, PSD Nature is also strongly present.

According to Kaplan (1992), a restorative place should also offer 'Fascination'. In the Rehabilitation Garden, the participants find an overall strong presence of PSD Nature. They talk about being out in nature; that they want to be alone with nature and that nature has a strong impact on them. This exposure provides them with spontaneous and fascinating experiences. The PSD Nature represents the force and power of nature, not man-made but on nature's own terms (Grahn and Stigsdotter, 2010), and seems to neither dominate the participants' thoughts, nor demand their directed attention. Instead, mental recovery is facilitated through soft fascination (Kaplan 2001). Many supportive locations also offer PSD Species Richness, where participants could find lots of opportunities for fascination.

Extent and fascination seem to be important in our NBR context and are also found to increase restorativeness in an urban context (Abdulkarim and Nasar, 2014). In a recent experimental study, Tyrväinen et al. (2014) found that an environment perceived as more coherent, better facilitated restoration and enhanced feelings of creativity and vitality. One could argue that the participants in this study used their creativity when expressing themselves, using what Nature offered to work with when handling their emotions. We interpret our results that supportive locations need to offer variations in fascinating attributes for one to react on. Nature is rich in these attributes, and offers quiet fascination (Kaplan et al.1998). 
This study has identified????some other qualities that are of crucial importance for NBR to function, in addition to Being Away, extent and Fascination. First, the site should contain a general character of Serene. PSD Serene represents a peaceful, calm place where one can stay and rest without disturbances from others also recognized as an important quality of urban green spaces (Tyrväinen et al. 2007; Skärbäck et al 2014). However, in the NBR context, disturbances could also originate in e.g. the colour scheme. Sensory stimulations should be moderate. In addition, privacy and anonymity is very important for the participants. Therefore, it is very important that the site is completely separate and secluded.

Finally, compatibility: This study suggests that this group of participants needed several locations where PSD Refuge is prominent. It also provides more specific instructions on how such sites should be designed. In addition, it indicates the need for this group of participants to be able to go away to seclusion, where they are able to release their pain, frustration and sadness .

\section{Implications for practice}

The result can be interpreted as that for this group of participants, who are depressed and suffer from stress-related mental illness, a large and clearly defined place will be vital (considering the health garden is $5 \mathrm{ha}$ ). Several studies show that urban parks which are well delimited from the surroundings promote restoration from stress and attention fatigue (e.g. Nordh et al 2009; Peschardt et al 2014). The result from this study indicates that size is an important parameter in the context. Grahn and colleagues (2005) and Skärbäck and colleagues (2014) argue that the size of an urban green space indeed is critical, e.g. for experiencing qualities of tranquility and nature - important not least for stress recovery. Other studies show that the size of children's outdoor environments is decisive for their play and well-being (Mårtensson et al 2009; Boldemann et al 2011). Similar to this study, several other studies claim that it is important to have access to green open spaces with secluded sites where the visitor may be in peace. The qualities they emphasize are similar to the woodland corner and the garden swing corner (see, for example, Stigsdotter et al., 2017b). This study also argues that it is important to have escape routes. The forest garden, with its many trees, is also an interesting environment for healthcare environments, or why not in urban parks (see e.g. Jiang et al 2016; Stoltz et al 2017)? Efforts are being made to develop practical tools for designing outdoor environments in care and rehabilitation (e.g. Bengtsson \& Grahn, 2014). The results presented here are in line with the suggestions being made in these tools, and could be used to further develop the tool.

\section{Methodological considerations}

Participants had just ended their rehabilitation time in the NBR programme and seemed to have a fresh recollection of what they had experienced during the last 12 weeks. One can wonder if 
informants were trying to please and give only a positive picture of the NBR but on the contrary they were critical and discussed both what they found positive and negative part of the NBR. This related to issues both related to the staff, other participants and the garden. Many expressed their gratitude for possibilities to have their voice heard. The locations identified as supportive were solitary places. Locations for social gathering and occupations performed as a group were discussed but no such locations where identified as 'a supportive location for the rehabilitation process'. It is of interest to look further into what kind of locations supports social interaction and the meaning of same for the rehabilitation process.

\section{Acknowledgement}

We would like to thank Cecil Konijnendijk van den Bosch and Diane Relf for valuable comments on the manuscript, the reviewers and all the participants, who generously shared their experiences of NBR in Alnarp Rehabilitation Garden.

Conflicts of Interest: The authors declare no conflict of interest.

\section{References}

Adbulkarim, D., Nasar J.L. 2014. Are liveable elements also restorative? Journal of Environmental Psychology, 38; 29-38.

Antonovsky, A. 1996. The salutogenic model as a theory to guide health promotion. Health Promotion International. Vol. 11, No 1. Oxford UniversityPress. Appleton, J. 1975. The experience of landscape. London:Wiley. Björk, J., Albin, M., Grahn, P., Jacobsson, H., Ardö, J., Wadbro, J.Ostergren. 2008. Recreational values of the natural environment in relation to neighbourhood satisfaction, physical activity, obesity and wellbeing. J. Epidemiol. Commun. Health. 62, e2.

Bengtsson, A., Grahn, P. 2014. Outdoor Environments in Healthcare settings: A quality evaluation tool for use in designing healthcare gardens. Urban Forestry \& Urban Greening 13: 878-891

Boldemann, C., Dal, H., Mårtensson, F., Cosco, N., Moore, R., Bieber, B., Blennow, M., Pagels, P., Raustorp, A., Wester, U., Söderström, M., 2011. Preschool outdoor play environments may combine promotion of children's physical activity and sun protection. Science and sports. 26, 72-82.

Emerson, R.M., Fretz, R.I., Shaw, L.L. 2011. Writing ethnographic fieldnotes, $2^{\text {nd }}$ ed. The University of Chicago Press, Chicago.

Grahn, P. 1991. Om parkens betydelse. (in Swedish) [On the meaning of parks]. Stad \& Land nr 93. Diss. Alnarp: Swedish University of Agricultural Sciences.

Grahn, P. and Sorte, G. J. 1985. Hur används parken? Om organiserade gruppers bruk av grönområden (in Swedish) [How are urban parks used? The use of urban green space by different groups of organizations] Research Report. The Swedish University of Agricultural Sciences, Alnarp.

Grahn, P., Stigsdotter, U.K. 2010. The relation between perceived sensory dimensions of urban green space and stress restoration. Landscape and Urban Planning 94: 264-27.

Grahn, P., Pálsdóttir, A.M., Ottosson, J., \& Jonsdottir, I.H. 2017. Longer Nature-Based Rehabilitation May Contribute to a Faster Return to Work in Patients with Reactions to Severe Stress and/or Depression Int. J. Environ. Res. Public Health, 14(11), 1310; doi:10.3390/ijerph14111310

Grahn, P. Stigsdotter, U. \& Berggren-Bärring, A-M. 2005. A planning tool for designing sustainable and healthy cities. The importance of experienced characteristics in urban green open spaces for people's health and well-being. In Conference proceedings "Quality and 
Significance of Green Urban Areas", April 14-15, 2005, Van Hall Larenstein University of Professional Education, Velp, The Netherlands.

Grahn, P. and van den Bosch, M., 2014. The impact of sound in health promoting environments. In: F. Mossberg, ed. 2014. Care for sound. Sound environment, healing \&health-care. Lund: Sound Environment Center, Lund University. pp. 43-59.

Grahn, P., Tenngart Ivarsson, C., Stigsdotter, U. and Bengtsson, I-L. 2010. Using affordances as a health promoting tool in a therapeutic garden. In C. Ward Thompson, P., Aspinall \& S. Bell (Eds.), Innovative approaches to researching landscape and health. Open Space: People Space 2. New York: Routledge; pp 116-54.

Gatersleben, B., Andrews M. 2013. When walking in nature is not restorative - The role of prospect and refuge. Health and Place, 20; 91-101.

Hartig, T., Mitchell, R., de Vries, S., Frumkin, H. (2014). Nature and Health. The Annual Review of Public Health. http://publhealth.annualreviews.org. Doi: 10.1146/annurev-publhealth032013-182443.Hartig, T. Restorative Environments. 2004. Encyclopedia of Applied Psychology, Volume 3. Elsevier Inc.

Hayes, N. 2000. Doing Psychological Research. Gathering and Analysing Data. Open University Press: Philadelphia, PA, USA.

Jiang, B., Li, D., Larsen, L., Sullivan, W.C. 2016. A dose-response curve describing the relationship between urban tree cover density and self-reported stress recovery. Environment and Behavior 48 (4), 607-629. Change font type

Jonsdottir, I., Nordlund, S.E., Ljung, T., Gliese, K., Währborg, P., Wallin, A. 2012. Cognitive impairment in patients with stress-related mental exhaustion. Stress, The international journal of the biology of stress. doi: 10.3109/10253890.2012.708950

Kaplan, S. 1992. The restorative environment: Nature and human experience, pp 134-142 in: Relf, D. (Ed.) The role of horticulture in human well-being and social development. Portland OR:

Timber Press.

Kaplan, S. 1995. The restorative benefits of nature: Towards an integrative framework. Journal of environmental psychology, 15, 169-182.

Kaplan, S. 2001. Meditation, Restoration, and the Management of Mental Fatigue.

Environment and Behavior, 33: 480-506. DOI: 10.1177/00139160121973106

Kaplan, R., Kaplan, S., Ryan, R. L. 1989. With people in mind: design and management of everyday nature. Washington, D.C., Island Press.

Korpela, K. 1992. Adolescents' favourite places and environmental self-regulation. Journal of Environmental Psychology, 12, 249-258.

Korpela, K.M., Hartig, T., Kaiser, F., Fuhrer, U. 2001. Restorative experience and selfregulation in favourite places. Environment and Behaviour, Vol 33 No. 4, 572-589.

Korpela, K., Staats, H. 2014. The restorative qualities of being alone with nature. The handbook of Solitude: Psychological Perspectives on Social Isolation, Social Withdrawal, and Being Alone. First Edition. Edited by R. J. Coplan and J. C. Bowker. John Wiley \& Sons, Inc.

Lavesson, L. 2013. A pilot study of Rosen practitioners' experience s receiving a modified form of Rosen method bodywork in a garden setting. RMIJ, Volume 6, Issue 1; 5-16.

Maas, J., Verheij, R.A., de Vries, S., Spreeuwenberg, P., Schellevis, F.G., Groenewegen, P.P. 2009. Morbidity is related to a green living environment. Journal of Epidemiol Community Health; 0:1-7.

Mitchell, R., Popham, F. 2008. Effect of exposure to natural environment on health inequalities: an observational population study. The Lancet 372, pp. 1655-1660.

Mårtensson, F., Boldemann, C., Söderström, M., Blennow, M., Englund, J-E., Grahn, P., 2009. Outdoor environmental assessment of attention promoting settings for preschool children: part of salutogenic concept. Health and Place, 15 (4) 1149-1157.

Nordh, H., Hartig, T., Hagerhall, C., M., Fry, G. 2009. Components of small urban parks that predict the possibility for restoration. Urban Forestry and Urban Greening, 8, 225-235. 
Ottosson, J., 2001. The importance of nature in coping with a crisis: a photographic essay. Landscape Research, 26 (2), 165-172.

Ottosson, J., Grahn, P. 2008. The role of natural settings in crisis rehabilitation. How does the level of crisis influence the response to experiences of nature with regard to measures of rehabilitation? Landscape Research, 33, 51-70.

Ottosson, J., Grahn, P., 2005. Measures of restoration in geriatric care residence: The influence of nature on elderly people's power of concentration, blood pressure and pulse rate. Journal of Housing of the Elderly, 19 (3/4), 229-258.

Pálsdóttir, A.M. 2014. The Role of Nature in Rehabilitation for individuals with stress-related mental disorders. Alnarp Rehabilitation Garden as Supportive Environment. Doctoral Thesis No. 45. Acta Universitatis Agriculturae Sueciae, Alnarp.

Pálsdóttir, A. M., Grahn, P., Persson, D. 2014. Changes in experienced value of everyday occupations after nature-based vocational rehabilitation. Scandinavian Journal of Occupational Therapy. Early Online, 1-11.

Pálsdóttir, A.M., Stigsdotter, U.K., Grahn. P. 2011. Preferred qualities in a therapy garden that promote stress restoration. Conference Proceedings, 27-29 June. Research into inclusive outdoor environment s for all. Open Space/People Space, Edinburgh.

Pálsdóttir, A.M., Persson, D., Persson, B., Grahn, P. 2014. The Journey of Recovery and Empowerment Embraced by Nature - Clients' Perspectives on Nature-Based Rehabilitation in Relation to the Role of the Natural Environment. Int. J. Environ. Res. Public Health 2014, 11(7), 7094-7115.

Peschardt, K.K, Stigsdotter, U.K., Schipperrijn, J. 2014. Identifying features of pocket parks that may be related to health promoting use, Landscape Research, DOI:

10.1080/01426397.2014.894006

Poulsen, D.V, Stigsdotter, U.K. and Refshage, A.D. 2015. Whatever happened to the soldiers? Nature-assisted therapies for veterans diagnosed with post-traumatic stress disorder: A literature review. Urban Forestry \& Urban Greening 14, 438-445.

Robson, C., 2011. Real world research. A resource for users of social research methods in applied settings. 3rd edition. John Wiley \& Sons Ltd, U.K.

Scopelliti, M., Giuliani, M.V. 2004. Choosing restorative environments across the lifespan: A matter of place experience. Journal of Environmental Psychology, 24; 423-437.

Skärbäck, E., Björk, J., Stoltz, J., Rydell-Andersson, K. Grahn, P. 2014. Green perception for wellbeing in dense urban areas - A tool for socioeconomic integration. Nordic Journal of Architectural Research, 26(2): 179-205.

Staats, H., Hartig, T. 2004. Alone or with a friend: A social context for psychological restoration and environmental preferences. Journal of Environmental Psychology, 24; 199211.

Searles, H.F., 1960. The nonhuman environment in normal development and in schizophrenia. International Universities Press, New York.

Stigsdotter, U.K. 2014. Nacadia Healing Forest Garden, Hoersholm Arboretum, Copenhagen, Denmark, in C. Cooper Marcus \& N. Sachs, Therapeutic Landscapes: An Evidence-Based Approach to Designing Healing Gardens and Restorative Outdoor Spaces. New York, John Wiley\& Sons. Pp.198-205.

Stigsdotter, U.K., Ekholm, O., Schipperijn, J., Toftager, M., Kamper-Jørgensen, F., Randrup, TB. 2010. Health promoting outdoor environments - Associations between green space, and health, health-related quality of life and stress based on a Danish national representative survey. Scandinavian Journal of Public Health, 38 (a) pp. 411-417.

Stigsdotter, U., Grahn, P. 2003. Experiencing a Garden: a Healing Garden for People suffering from Burnout Diseases. Journal of Therapeutic Horticulture; 13, 38-48.

Stigsdotter, U.K., Palsdottir, A. M., Burls, A., Chermaz, A., Ferrini, F., Grahn, P., 2011. Nature-based therapeutic interventions. In Nilsson, K., Sangster, M., Gallis, C., Hartig, T., de Vries, S., Seeland, K., \& Schipperijn, J., editors. Forest, trees and human health.

Dordrecht: Springer, pp. 309-42. 
Stigsdotter, U.K., Corazon, S.S., Sidenius, U., Kristiansen, J., Grahn, P. 2017a. It is not all bad for the grey city - A crossover study on physiological and psychological restoration in a forest and an urban environment. Health \& Place 46, 145-154.

Stigsdotter, U.K., Corazon, S.S., Sidenius, U., Refshauge, A.D., Grahn, P. 2017b. Forest design for mental health promotion-Using perceived sensory dimensions to elicit restorative responses. Landscape and Urban Planning 160, 1-15.

Stoltz, J., Lundell, Y., Skärbäck, E., Annerstedt van den Bosch, M., Grahn, P., Nordström, E-M., Dolling, A. 2017. Planning for restorative forests: describing stress-reducing qualities of forest stands using available forest stand data. Eur J Forest Res DOI 10.1007/s10342-016-0974-7.

Tenngart Ivarsson, C. 2011. On the use and experience of a health garden. Exploring the design of the Alnarp Rehabilitation Garden. Doctoral Thesis No 2011:89. Swedish University of Agricultural Sciences, AlnarThe computer made the changes Good luck Tenngart Ivarsson, C., Hägerhäll, C. 2008. The perceived restorativeness of gardens - Assessing the restorativeness of a mixed built and natural scene type. Urban Forestry \& Urban Greening, 7, 107-118.

Tyrväinen, L., Ojala, A., Korpela, K., Lanki, T., Tsunetsugu, Y. and Kagawa, T. 2014. The influence of urban green environments on stress relief measures: A field experiment. Journal of Environmental Psychology, 38, 1-9.

Ulrich, R.S., Simons, R.F., Losito, B.D., Fiorito, E., Miles, M.A., Zelson, M. 1991. Stress recovery during exposure to natural and urban environments. Journal of Environmental Psychology, 11, 201-230.

Van den Berg, A., Maas, J., Verheij, R.A., Groenewegen, 2010. Green space as a buffer between stressful events and health. Social Science \& Medicine, 70(8), 1203-1210. van den Bosch, M.A.; Östergren, P-O; Grahn, P.; Skärbäck, E.; Währborg, P. 2015. Moving to serene nature may prevent poor mental health - Results from a Swedish longitudinal cohort study. Int. J. Environ. Res. Public Health 2015, 12, 7974-7989 Währborg P, Petersson IF, Grahn P. 2014. Nature-assisted rehabilitation for reactions to severe stress and/or depression in a rehabilitation garden: long-term follow-up including comparisons with a matched population-based reference cohort. J Rehabil Med. 46:271-6. World Medical Association Declaration Helsinki, version from 2008. Available at [http://www.wma.net/en/30publications/10policies/b3/.] Accessed 20 March 2013. Yin, R.K. 2009. Case study research design and methods. 5th ed. Thousand Oaks, CA: SagePublication. 
Figure Caption 


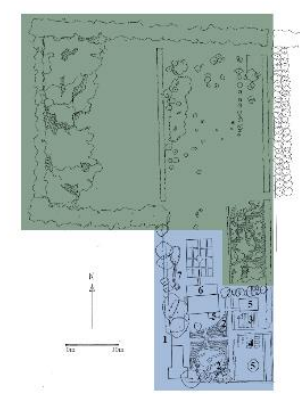

Figr-1 


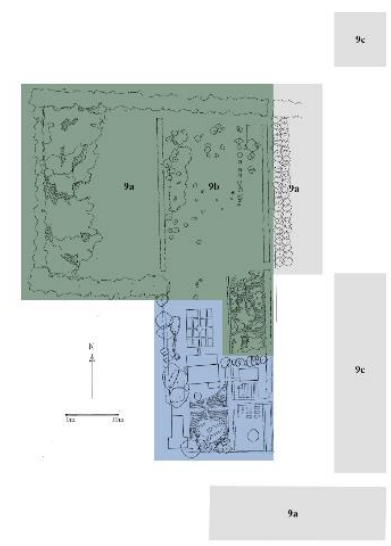

Figr-2 